\title{
Athlete's nutrition knowledge and their perception and satisfaction in the foodservice quality of the athlete's cafeteria
}

\begin{abstract}
This study investigated athletes' perceptions and satisfactions on the foodservice quality of the athlete's cafeteria as well as their knowledge on nutrition. Four dimensions namely food quality, meal service quality, staff/service issues, and dining environments and their overall satisfactions were investigated. Athletes were most satisfied with the meal service quality dimension and least satisfied with the food quality dimension. The food quality and staff/service issues dimensions were found to be the two predictors of overall foodservice satisfaction. Thus, more implementations should be taken to enhance the quality of foods and services at the cafeteria that catered for the athletes.
\end{abstract}

Keyword: Foodservice; Athletes' nutrition knowledge; Foodservice satisfaction; Food quality 